\title{
THE RISK OF HYDROGEN EXPLOSION IN A SUBMARINE P.I CATALYTIC COMBUSTION OF HYDROGEN
}

Ryszard Kłos

Polish Naval Academy, Department of Underwater Work Technology in Gdynia, Poland

\section{ABSTRACT}

The series of articles discuss issues related to conducting high risk projects on the example of modernisation of hydrogen incinerators on a submarine. The article depicts a technical problem situation connected with catalytic hydrogen combustion on a submarine. Key words: submarine, risk of hydrogen explosion.

ARTICLE INFO

PolHypRes 2016 Vol. 56 Issue 3 pp. 7 - 24

ISSN: 1734-7009 eISSN: 2084-0535

\section{Original article}

DOI: $10.1515 /$ phr-2016-0015

Delivery date: $02.07 .2016 \mathrm{r}$.

Pages: 18 , figures: 6 , tables: 1

Date of approval for print: 15.08.2016r.

page www of the periodical: www.phr.net.pl

Publisher

Polish Hyperbaric Medicine and Technology Society 


\section{INTRODUCTION}

The scenario considered in this article concerns the possibility of modernising hydrogen incinerators, the task consisting in the replacement or regeneration of catalyst cartridges, with consideration to the following issues:

- resignation from supplies from Russia,

- an extremely short period of time for project implementation,

- low project budget,

- pressure caused by the fact that the project constituted only a small part in the scope of the renovation works on the submarine,

- lack of infrastructure to conduct this type of works and insufficient competences within research on catalysis.

The Polish Naval Academy has always dealt with problems connected with logistics and utilisation of military equipment and arms. Despite the large project risk, keeping the Academy's good reputation as a centre for the grouping of specialists in the utilisation of military equipment and arms was taken into account as a crucial condition.

The basis for success in highly risky projects consists not only in applying a proper management technique ${ }^{1}$ and being focused on the objective, but firstly in having a disciplined and qualified team of specialists that know how to work together. The Institute of Underwater Works Technology has been developing its competences within teamwork for decades, undertaking the implementation of ambitious and therefore risky projects, including industrial research, implementation works and utilisation of various types of techniques ${ }^{2}$.

The organisation's own experiences, within the construction of devices for catalytic hydrogen combustion, have been described previously as an outcome of a project commissioned by the Armament Policy Department of the Ministry of National Defence entitled: "Life support systems on submersible vessels" agreement no. 20/DPZ/3/OTM/S/WR/MON/2002/706 of 11.09.2002 [1].

\section{INTRODUCTION}

The fire protection system provided on a submarine, which by the nature of its purpose works independently, constitutes a potential problem from the point of view of the crew's safety and the security of any given combat mission. One of the factors that forms the fire and explosion hazard on board is hydrogen, which can be emitted continuously, however reveals the greatest intensity during charging of the integral battery packs.

Ensuring battery compartments are airtight significantly reduces external hydrogen emission. For this purpose the said compartments are characterised by a special construction of sealed containers with sealed manholes. Nonetheless, we should always take into account the possibility of hydrogen leakage due to its high volatility and penetrative properties.

Submarines are secured against hydrogen leakage from the compartments by monitoring its concentration in the atmosphere of particular compartments and ventilating battery compartments to prevent its accumulation.
The most common form of prevention consists of the internal monitoring of hydrogen concentrations in battery compartments conducted as part of the general monitoring of the vessel's atmosphere. On some vessels it is possible to drawer atmospheric samples from battery compartments via special sampling pipes, allowing the composition of the battery compartments' atmosphere to be analised using a portable analytical device.

Alerts, in the event of an uncontrolled hydrogen leakage from battery compartments into the areas accommodated by the crew, are commonly realised by the system of sensors located near the manholes and in selected staff rooms. Even with the automated detection system in service, it is good practice, for an on-duty officer to periodically tour areas accomodated by the crew with a portable analyser, testing for hydrogen concentrations.

Ventilation of battery compartments can be performed in an open-circuit system or with hydrogen combustion in a closed-circuit system. An open ventilation system is most frequently used during battery charging while in a port or floating on the surface in an on-water or semi-submerged position. In case of emergency there is usually a possibility to release the air from battery compartments to larger rooms. This serves to dilute hydrogen in the air volume of the compartment. Such a variant is realised only as an emergency procedure in a combat situation, for instance during a rapid submersion following forced charging of the battery on the surface.

Hydrogen combustion is implemented through catalytic hydrogen combustion in the air. The catalytic bed is located in hydrogen incinerators. Discharge from the combustion system is realised to the atmosphere of the submarine. Incinerator operation is allowable only when hydrogen concentration does not exceed the lower flammability limit. Therefore, the hydrogen combustion system should be operated under supervision.

On the basis of the context analysis conducted according to the $S W O T^{3}$ method the following conclusions were drawn:

- $\quad$ For the time being the market does not offer good solutions that would replace the existing hydrogen combustion systems.

- National research led to the development of technology demonstrators that raise hope regarding quick development of effective systems to replace the existing installations.

- The available laboratory base is not equipped with the special test benches needed to inspect hydrogen combustion installations, hence during the performance of minor immediate repairs it is enhanced on an ad hoc basis.

- The possessed experience gives hope regarding the performance of modernisation on hydrogen combustion systems although it also entails a certain risk that such activities will not bring the desired effects.

\section{Problem Situation}

The problem related to the disposal of hydrogen generated in the technological process, which creates the risk of an explosion, is tackled in such branches as: the nuclear power industry [2], the space [3], the petroleum industry [4], etc. The considered problem situation is 
connected with hydrogen generation during the use of batteries on a conventional submarine.

The most hydrogen can be generated during forced charging of an integral battery set in a port or during a mission at sea. In both cases the hydrogen generated in the sealed battery compartments can reach an explosive concentration.

During combat activities of a conventional submarine there may be a need to charge of the integral battery set at sea. Charging must be performed on the surface, or in semi-submersion in order to supply air to the combustion engines powering the generators ${ }^{4}$.

Commonly, this is conducted under the cover of night with a threat of discovery by surface and air reconnaissance patrols ever present. In situations where contact with the enemy is possible, the charging process should be as fast as possible, thus causing a significant increase of temperature in the battery cells. In the event of the opponent showing up during charing, it would be required to perform rapid submersion with hot batteries.

Such a situation involves the risk of hydrogen emission by the batteries in to compartments whch can no longer be ventilated in an open-circuit system to the atmosphere. Cell ventilation with the air from the atmosphere of a submarine with the use of hydrogen combustion systems prevents hydrogen accumulation in the compartments and its emission outside them.

The possibility of an occurrence of an explosive atmosphere is monitored by measurements of hydrogen concentration in battery compartments. Our submarines are also equipped with a measurement system in the parts beyond the battery compartments, particularly over the manholes to battery rooms. A description of a typical monitoring system onboard a submersible vessel has been described in previous articles and so will not be presented in this paper [1].

Catalytic combustion of hydrogen contained in the air is performed with the use of chemically activated metals or mixes of metals, such as: $\mathrm{Co}, \mathrm{Rh}, \mathrm{Ir}, \mathrm{Pd}, \mathrm{Pt}, \mathrm{Ag}$, $A u$ etc. $[5,3]$.

The most common type of catalysts are threeway $^{5}$ car exhaust gas combustion catalysts $^{6}$. Turbine engines are also equipped with systems of this type. Catalyst ignition systems were applied for many years in the small engines of satellites used for the correction of their position [3]. Currently, intensive research into the catalytic systems of hydrogen-based fuel cells is being carried out [6]. Catalytic systems built on the basis of the indicated metals are used in numerous applications for the purpose of work environment protection [7].

Commonly, metallic catalysts are constituted by crystallites $^{7}$ in ceramic matrices usually based on oxides of: $\operatorname{Si}(\ldots) \mathrm{Mg}$ and $A l$. The spacial structure of the crystallites of the noble metals and the oxide ceramic matrix is the key parameter for the efficiency of the processes of catalysis [3].

The process of hydrogen combustion in the air most commonly employs $P t$ and $P d$ catalysts or the mixture of $P t-P d$ [2]. Patent no. CA1314277 C suggests the use of a catalyst on the basis of $P d$ and an admixture of $\mathrm{Ni}$ and $\mathrm{Cu}$.

\section{DEFINITION PHASE}

The definition phase defines the project scope and confirms the feasibility of its implementation. It defines basic $C T Q$ requirements8, critical from the point of view of quality assurance.

The primary task consisted in restoring the efficiency of a catalytic converter for hydrogen combustion in the system of battery facilities ventilation used for:

- $\quad$ air flow ventilation within the range from zero to the maximum value $\dot{V}_{0} \in[0 ; 150] \mathrm{m}^{3} \cdot h^{-1} \triangleq$ $[0 ; 2500] \mathrm{dm}^{3} \cdot \mathrm{min}^{-1}$

- efficient combustion of hydrogen contained in the ventilated air evacuated from the battery facilities, operating in the range from zero to the maximum flow rate $\dot{V}_{\mathrm{H}_{2}} \in[0 ; 4,5] \mathrm{m}^{3} \cdot h^{-1} \triangleq$ $[0 ; 75] \mathrm{dm}^{3} \cdot \mathrm{min}^{-1}$ suited to the ventilation flow in such a way that the air-hydrogen mixture does not contain hydrogen in a concentration exceeding lower flammability limits.

Hydrogen incinerators should ensure a minimum tenfold reduction of hydrogen concentration related to its maximum concentrations in the airhydrogen mix.

In addition to the main objective the following tasks were to be implemented:

- Performance of a measurement station ensuring measurements within the required range and reliability level,

- Performance of a station for the production of hydrogen-air mixes guaranteeing the desired composition at the required reliability level,

- Selection of potential catalyst types,

- Performance of a station and conducting tests on selected catalysts,

- Performance of a station and conducting inhouse and acceptance tests on hydrogen incinerators.

\section{Process MEASUREMENT PHASE}

The process measurement phase entailed conduction of a repeated evaluation of quality requirements $C T Q$, preliminary risk analysis and determining the main response of the hydrogen combustion system for acceptance tests. The evaluation of the measurement system was proposed and conducted for the planned tests and trials. A data collection plan was established and measurement process efficiency standards were defined.

The measurement system consisted of two pellistor sensors ${ }^{9}$ of POLYTRON $2 X P E x$ type. The sensors were connected with the use of analog-to-digital converters, utilising dedicated software.

The flow of analysed gas through the sensors was regulated with electronic flowmeters connected in series with a rotameter enabling flow visualisation outside the computer software. Metrological tests and analysis of the $R \& R^{10}$ of the efficiency of the measurement system for monitoring the main system response were conducted. The said tests had been previously described and will be omitted in this paper[8,9].

This project phase defines critical quality requirements $C T Q$ for the products and processes that support the process of overhaul of the hydrogen incinerators. Nine quality requirements were defined as critical CTQ: probity/accuracy, timeliness, adequacy, compatibility, low maintenance, efficiency, reliability, experience and $S O P$, and redundancy. By way of $Q F D^{11}$ 
analysis, ranking of the three most important quality requirements for $C T Q$ was performed: probity/accuracy, adequacy, reliability.

This project phase defines critical quality requirements $C T Q$ for the products and processes that support the process of overhaul of the hydrogen incinerators. Nine quality requirements were defined as critical CTQ: probity/accuracy, timeliness, adequacy, compatibility, low maintenance, efficiency, reliability, experience and $S O P$, and redundancy. By way of $Q F D^{12}$ analysis, ranking of the three most important quality requirements for $C T Q$ was performed: probity/accuracy, adequacy, reliability.

8 key intermediate products in the form of systems were determined: measurement of hydrogen content in the air, measurement of incinerator parameters, measurement of air and hydrogen flow, hydrogen flow dosage, air supply, hydrogen and air

a)

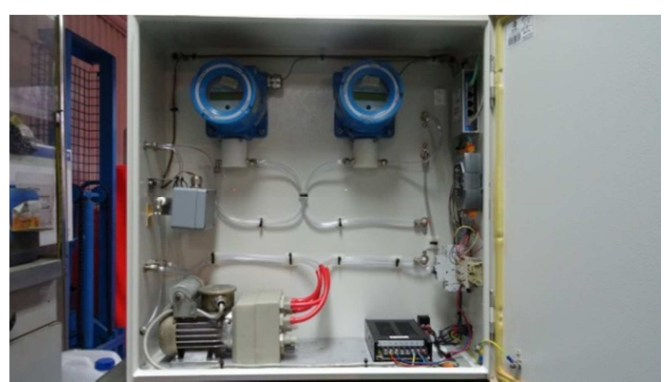

c)

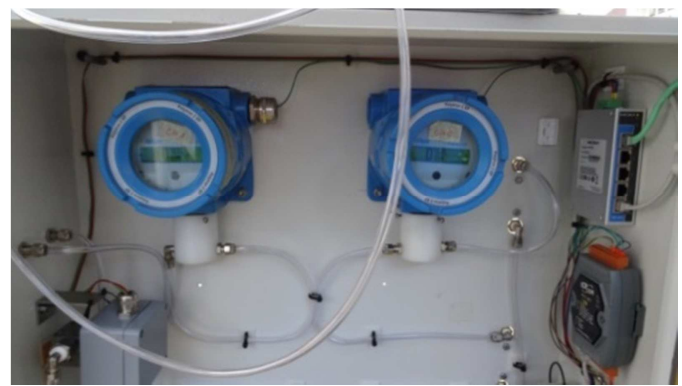

mixing, performance of stations for acceptance tests and trials. It was determined that the following partial products are crucial for the functionality of the final product: a hydrogen concentration measurements system, a flow measurement system, a hydrogen dosage system, a gas mixing system, a catalyst testing station and an acceptance testing station. The following systems have a moderate effect on the functionality of the final product: incinerator temperature measurement, air stream supply.

The operational objectives should encompass careful monitoring of the values of the implemented processes by measurement of the hydrogen content before and after the incinerator. The catalyst testing process is of key importance for the overhaul process of hydrogen incinerators. b)

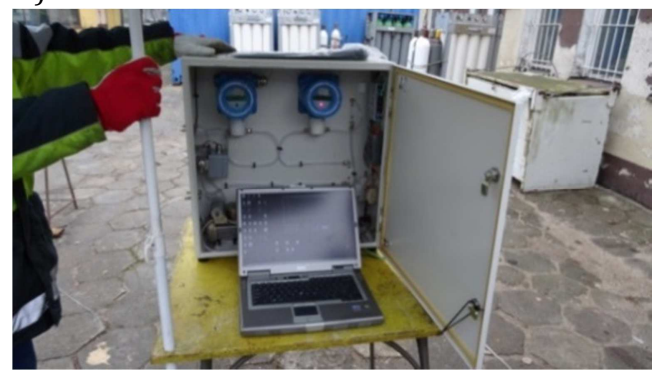

d)

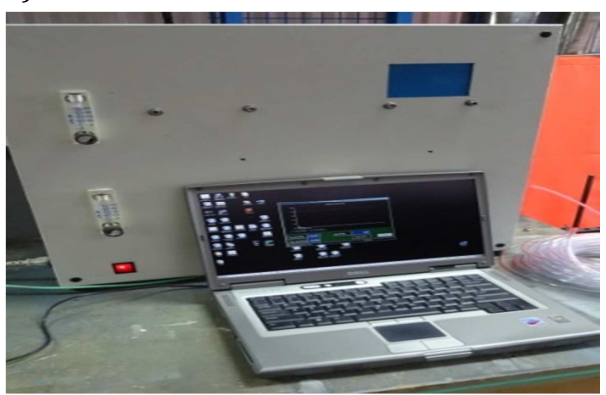

Fig. 1. Scheme representing a complete measurement system meeting the CTQ quality requirements for the overhaul process on hydrogen incinerators: a)station view from the supply pump, analysers, power supply and signal transmission components b)complete measurement station during testing c)view on POLYTRON 2 XP Ex pellistor analysers, on the right wall visible module for network communication management, below - module fulfilling the role of an analog-to-digital signal converter from pellistor analysers and converter to the network communication system, on the left wall pressure differences sensor d) view of a complete measurement station from the front along with rotameters and flow control valves.

\section{Process ANALYSIS PHASE}

During the conducted tests, the capacity and efficiency of the hydrogen combustion process was characterised with the use of selected catalysts. Moreover, attempts were made to identify sources of variation in the hydrogen combustion process. 
Basic catalyst parameters for $0.5 \%_{m} P t$ type $G A-20 P t$ and $0.5 \%_{m} P d$ type $G A-50 P d$.

\begin{tabular}{lc} 
Parameter & Value \\
\hline Metal content in matrix $\mathrm{Al}_{2} \mathrm{O}_{3}$ & $0.5 \%_{\mathrm{m}}$ \\
\hline Catalytic deposit density & $\varepsilon \cong 50 \%$ \\
\hline Bulk density & $d \cong 0.75 \mathrm{~kg} \cdot \mathrm{dm}^{-3}$ \\
\hline Substitute diameter & $d_{S} \cong 5 \mathrm{~mm}$ \\
\hline Statistical efficiency of hydrogen oxidation exceeds & $\cong 100 \%$ \\
$100^{\circ} \mathrm{C}$ & $\begin{array}{l}\text { Catalyst production is based on the use of } \mathrm{Al}_{2} \mathrm{O}_{3} \text { pellets with the diameter of } \\
\phi \in[4 ; 8] \mathrm{mm} \text {, however the share of particular fractions alters between supplies. }\end{array}$ \\
\hline
\end{tabular}

A key element in carrying out modernisation of the hydrogen disposal system rests in solving the problem of replacement of the catalyst cartridges. Catalyst selection was to be based on national possibilities or those of $E U$ or NATO countries.

The previous studies on this subject matter were performed with the use of $0.5 \%$ platinum on $3 \mathrm{~mm}$ alumina type 73 pallets manufactured by Johnson Matthey PLC Catalyst [1] Market analysis revealed a reliable catalyst producer operating in Poland - an innovation and implementation company called Katalizator Ltd.

Following an initial study, it was proposed to replace the content with palladium $0.5 \%_{m} P d$ or platinum $0.5 \%_{m} P t$ catalysts available in two granulation types, $\phi \in[2 ; 3] \mathrm{mm}$ and $\phi \in[4 ; 8] \mathrm{mm}$.

The maximum temperature for the continuous catalyst operation is equal to $t_{\max }<550^{\circ} \mathrm{C}$. Due to the necessity of desorption of water occurring during the reaction on the catalyst's surface, it should operated at a temperature lower than $t_{\min }>200^{\circ} \mathrm{C}$.

The choice of catalyst granulation was based on flow resistance. Since catalyst granulation significantly differed in shape in the direction of travel towards the lower substitute diameter, the resistance of the cartridges was stronger. Increasing the flow resistance of catalyst cartridges can reduce the efficiency of battery compartments ventilation on a submarine.

This parameter should be observed, otherwise there is a risk of a need to redesign the incinerator equipment ${ }^{13}$ and, thus, increase the cost of modernisation. This had not been considered in the project scope, its calculation and schedule. Therefore, before taking the final decision on catalyst purchase, a sample of its base constituted by the alumina granulation was purchased for the purpose of carrying out flow resistance tests.

The experiment proved that an increase of flow resistance $\Delta p$, connected with the application of a new filling, causes a flow reduction of $\dot{V}_{0}$ ventilation air at an acceptable level, guaranteeing the maintenance of the ventilation capacity of the battery rooms with the use of the same fan [8]. Flow measurement results have been contained in the second cycle of articles and will be published later.

A permanent dosage system, composed of a nozzle operating in conjunction with a hydrogen dosage regulator into the stream of air, was used to obtain hydrogen-air mixtures. The design, construction and tests performed on this system have been described in the third article of the cycle to be published at a later date. Also there the author describes issues connected with work safety related to handling hydrogen-air mixes.
In line with the documentation of the incinerator subjected to modernisation, it was necessary for the device to work below the lower flammability limit of the hydrogen-air mix, at the level of approximately $C\left(\mathrm{H}_{2}\right) \leq 3 \%$. Low temperature and high air humidity constituted additional conditions favourable in terms of the safety of the conducted research ${ }^{14}$.

The measurement panel has been located behind a plexiglass door to ensure the safety of the crew in the event of explosion - fig. $2 \mathrm{~d}$. The test site was located under the tent visible in fig. 2 c, surrounded on two sides by the walls of buildings for the purpose of fragmentation protection in the event of an explosion. The hydrogen cylinder station was located around the corner of the building, outside the fragmentation area.

The catalyst tests were performed with the use of a fan disassembled from a submarine - fig. $2 c$. In this configuration the supplied hydrogen could periodically return from the pipe reactor. Despite the applied tilting of the air inlet and supplying of an additional elbow pointed downwards, fig. 2a,

it was not possible to obtain constant hydrogen content in the drawn air, its content being subject to fluctuations - fig.2b. However, this situation was approved by the project holder due to the fact that the priority was to ensure operation of a nearly completed system rather than guarantee permanent composition of the air-hydrogen mix, since such a state more precisely mimics system behaviour under real operating conditions. 
a)

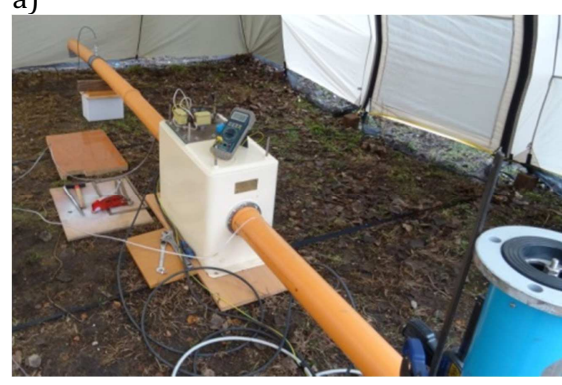

c)

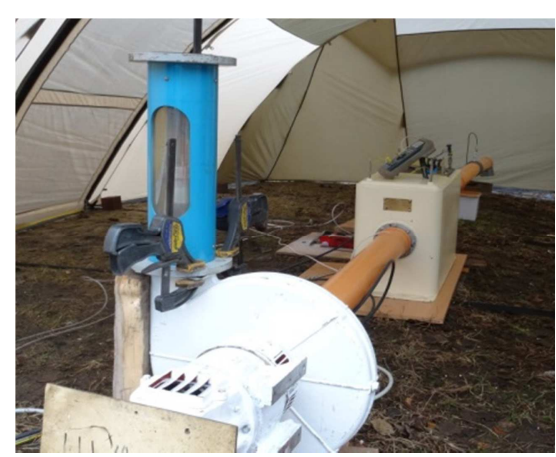

b)

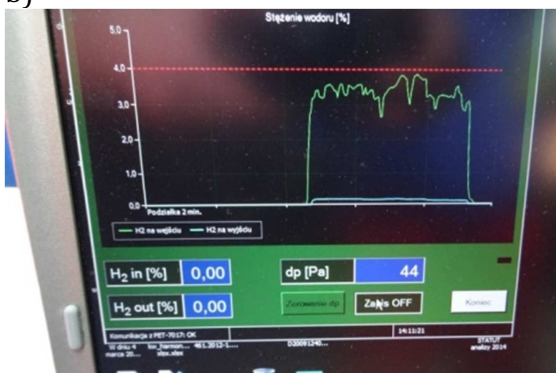

d)

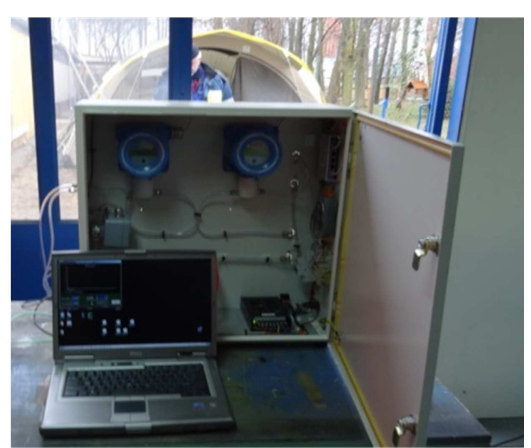

Fig.2. Catalyst testing station: a)station with connected analytical routes, hydrogen dosage to incinerator power supply type PD - $3 \mathrm{~A}$ and connections to thermometric platinum sensors type PT - 100; b) measurement results imaging; c)research station with suction fan and rotameter visible in the foreground; d)analytical station behind a protective door.

The hydrogen-air mix was generated by adjusting the pressure in the nozzle dosing the hydrogen to the previously forced air flow. Preliminary tests were conducted on hydrogen incinerators filled with cartridges with the previously selected platinum catalyst $0.5 \% \mathrm{~m} P$, $G A-20 P t$ type, and palladium $0,5 \%{ }_{m} P d$ catalyst, $G A-50 P d$ type. Testing was performed on bed volumes of four, three, two

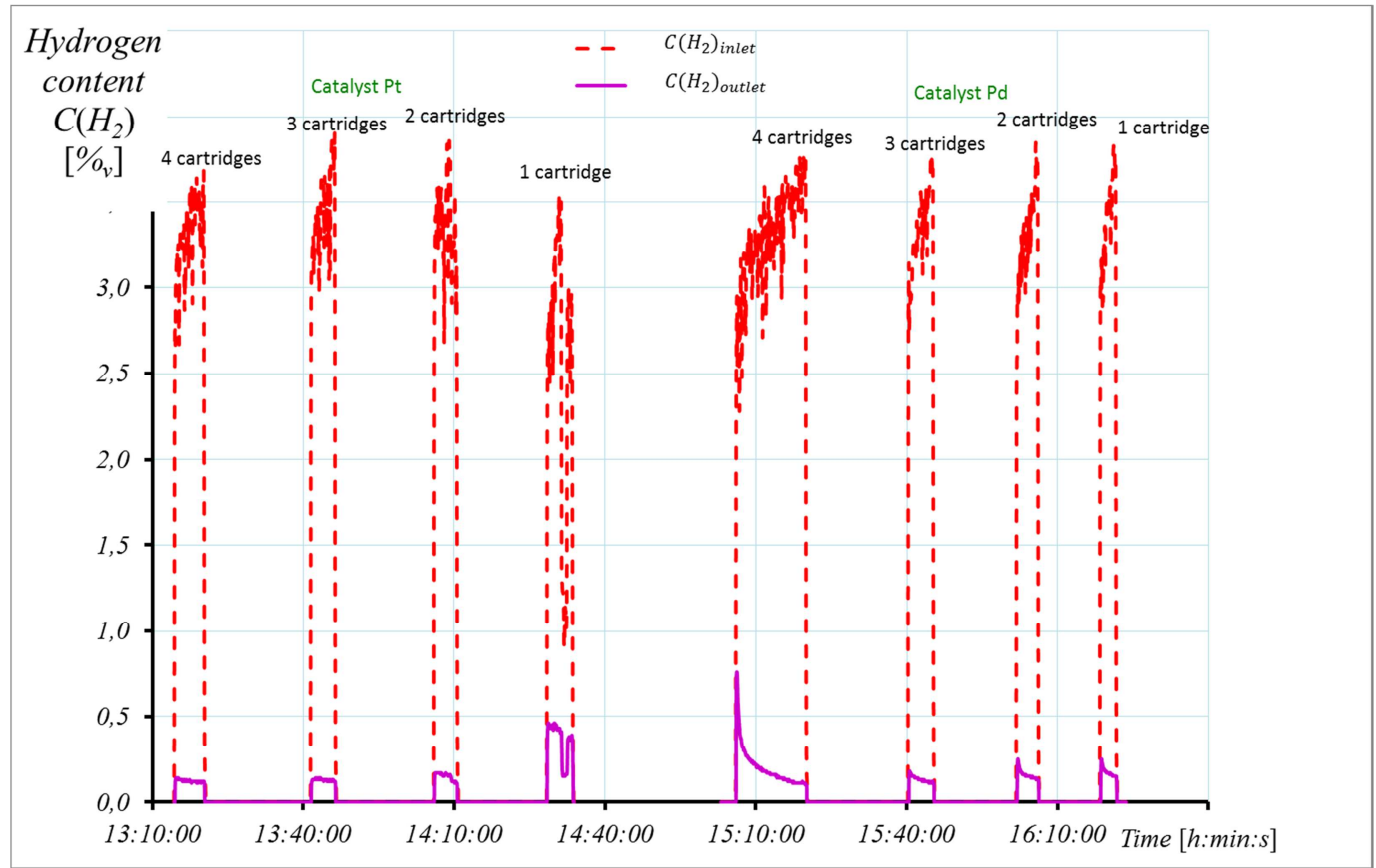

Fig. 3. Preliminary test results for the activity of catalysts: $0.5 \%_{m} P t, G A-50 P t$ type, $0.5 \%_{m} P d, G A-50 P d$ type with bed volumes of $1-4$ catalyst cartridges. 
and one cartridge with a catalyst.

Measurement results are presented in fig.3. Initial measurements were performed over a relatively short period of time due to the observed rapid temperature increase. It seemed that further testing without temperature monitoring could result in incinerator damage or thermal explosion. Moreover, a significant humidity emission was noted which suggested that the catalyst deposit was not yet sufficiently dry and failed to express full activity. This was particularly visible in activity results for catalyst $G A-50 P d$ where later measurements performed on a single cartridge indicated a higher activity than those conducted previously for four cartridges.

Also, measurements were performed on the original fillings of hydrogen catalyst incinerators which are shown in fig.4. As before, the measurements were conducted for catalytic deposit volumes of four, three, two and one cartridge. Despite the dryness and longer operation, the old fillings revealed decreased activity as compared to

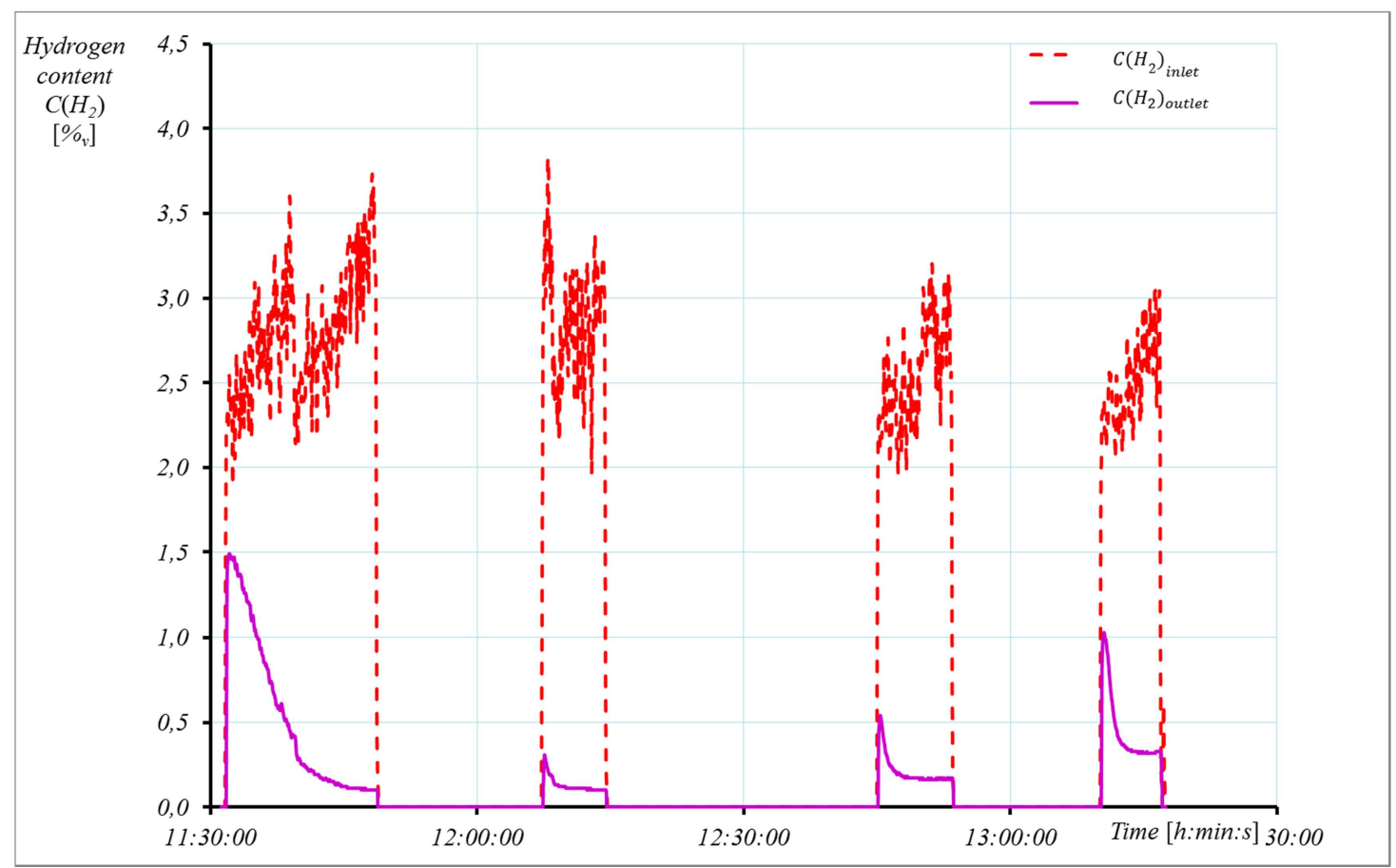

Fig.4. Measurement results with the use of original fillings and bed density of 1-4 catalyst cartridges.

the new ones. However it should be noted that the incinerators met the final acceptance requirements, and in fact, they could be authorised for further operation without the need for bed replacement and merely performing its conditioning.

The results of the preliminary tests confirmed sufficient activity of the selected catalytic converters, and thus the feasibility of meeting the critical quality requirements $C T Q$ assumed in the project. It was also found that the original fillings could meet the said requirements following the conditioning process.

On the basis of the test results it was decided to exert some effort to ensure that the hydrogen-air mix leaving the system would contain only trace hydrogen content, thus increasing the quality requirements $C T Q$ imposed with regard to the hydrogen incinerators' overhaul.

The results demonstrated that it is sufficient to utilise two pallets with traditional cartridges, one with a palladium catalytic converter $0.5 \%_{m} P d, G A-50 P d$ type and one pallet with a platinum catalyst $0.5 \% \mathrm{~m}$, $G A-20 P t$ type. This allowed implementation of the entire project scope, saving funds for the purchase of catalysts and reducing flow resistance by the catalyst bed.

Such a bed composition will also allow the drawing of conclusions from the further utilisation of all three catalyst types, which will enable selection of the best of them in the future.

The system in question is quite simple with regard to its model ${ }^{14}$ in the assumed project scope, however the hydrogen combustion process during operation will be conducted in stable, ambient conditions, guaranteed by an automatic flow and temperature maintenance by the hydrogen incinerator equipment. On this basis it was decided to holdback from performing correlation analysis between the hydrogen combustion 
process efficiency and environmental parameters. Also, due to time limitations it was not possible to conduct a statistically reliable variability analysis.

\section{PROCESS IMPROVEMENT PHASE}

The modernisation strategy assumes that only the catalyst bed configuration is modified, with a calculation that does not require the introduction of any construction alterations in the hydrogen incinerator. Another project result consisted in collecting of information concerning the best catalyst type among those selected to be used in the incinerator. The knowhow had not been provided by the manufacturer, nor was it obtained in the course of our own research. Deposit configurations were tested during the conducted tests, which served as the basis for the acceptance trials.

In proposing the final solution it was necessary to consider all the defined critical quality requirements CTQ and the significant financial and time constraints. Hence, the project scope was implemented at the expense of the minimisation of the quality requirements $C T Q$.

Due to the possession of sufficient knowledge regarding the occurring deterministic phenomena in the problem in question, it was decided to holdback from performing statistical experiment modelling and $D O E^{15}$, with the validation of the adopted solution based solely on the acceptance tests' schedule, and determination of the definition of a defect, to prevent the adoption of the wrong solution.

Due to the imposed time limits and nature of the problem, it was decided to conduct experiments on a similar system which had been extracted from a submarine, differing from the shipboard equipment only by the simulated battery room modelled by a pipe reactor used to obtain the hydrogen-air mix. Therefore, the tests were conducted on a real scale, with the results not being transferred using a scale-up methods.

The tests on the initially proposed deposit configuration composed of four catalyst pallets: palladium $0.5 \%_{m} P d, G A-50 P d$ type, traditional, platinum $0.5 \%{ }_{m} P t, G A-20 P t$ type, and traditional are presented in fig.5.

As predicted, the test showed that it is possible to obtain nearly zero hydrogen concentration in the mix leaving the incinerator following catalyst bed conditioning. The zero level for this configuration is obtained within a time shorter than $t=5 \mathrm{~min}$. In the case of the thus configured bed it was possible to obtain an air flow at the level of $\dot{V}_{0} \cong 140 \mathrm{~m}^{3} \cdot \mathrm{h}^{-1}$, which is almost compliant with

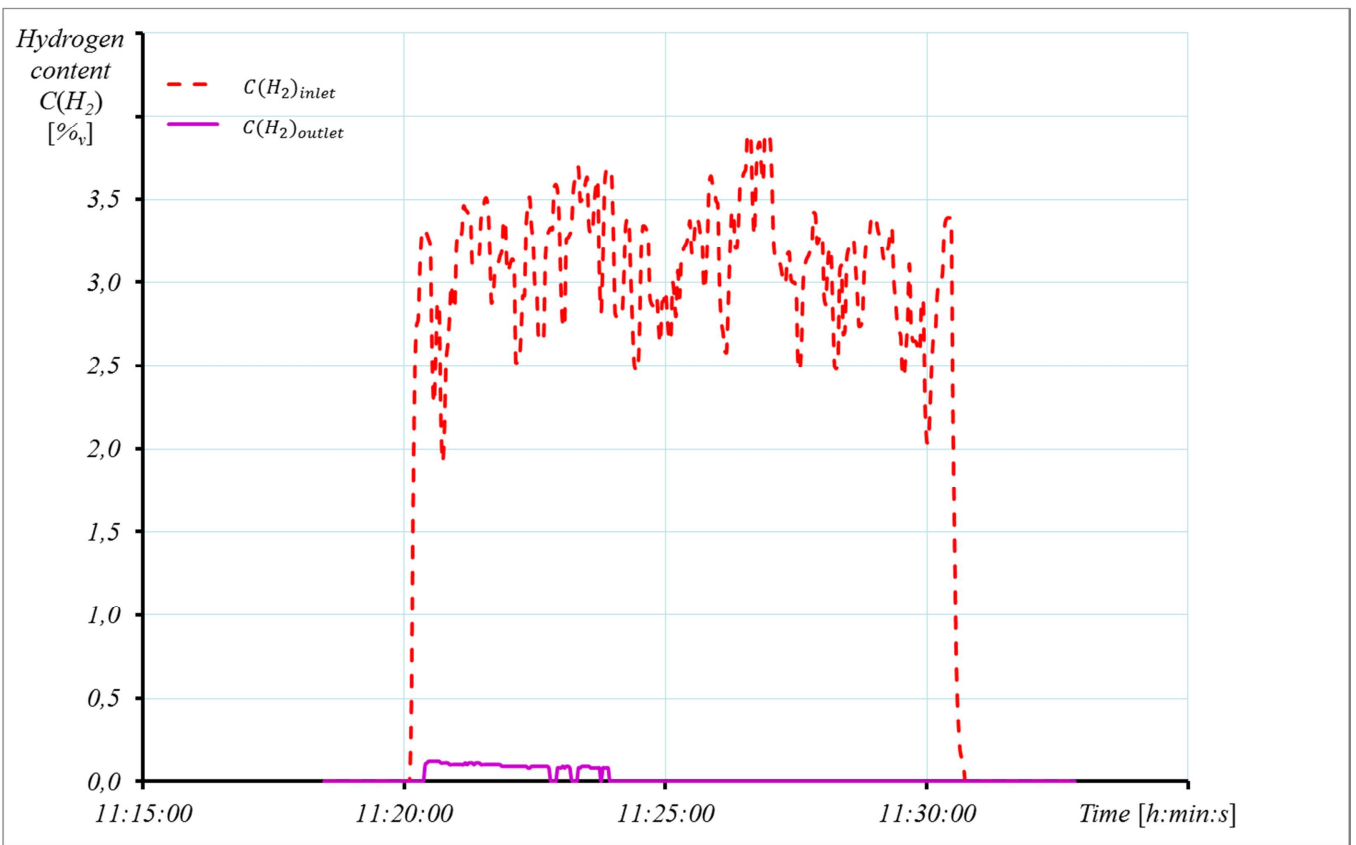

Fig.5. Test results for the initially proposed deposit configuration composed of four catalyst pallets: palladium $0.5 \%{ }_{\mathrm{m}} \mathrm{Pd}$, GA $-50 \mathrm{Pd}$ type, traditional, platinum $0.5 \% \mathrm{~m}$ Pt, GA - $20 \mathrm{Pt}$ type, and traditional.

the value marked by the manufacturer as nominal. However, this type of configuration causes significant local heating of the incinerator, exceeding a temperature of $t>300^{\circ} \mathrm{C}$, which leads to the damaging of temperature measurement system components.

The result of this test suggests a greater activity in terms of hydrogen oxidation capacity in the case of the palladium catalyst, thus it was decided to swap the places of the platinum and palladium catalysts. Traditional cartridges can fulfil the role of a filler when placed behind the new catalysts, or of initial combustion when placed at the beginning of the catalyst bed.
It was decided to propose a different placement of pallets with the catalytic fillings: platinum catalyst pallet, palladium catalyst pallet, two pallets of traditional catalyst.

Measurement results for this catalyst bed configuration are presented in fig.6. The adopted bed configuration ensures temperature stabilisation in spaces between the pallets at the level below $t<200^{\circ} \mathrm{C}$, which is optimal for the operation of catalysts of this type. Temperature at the outlet only slightly exceeds the temperature at the inlet of the incinerator. 


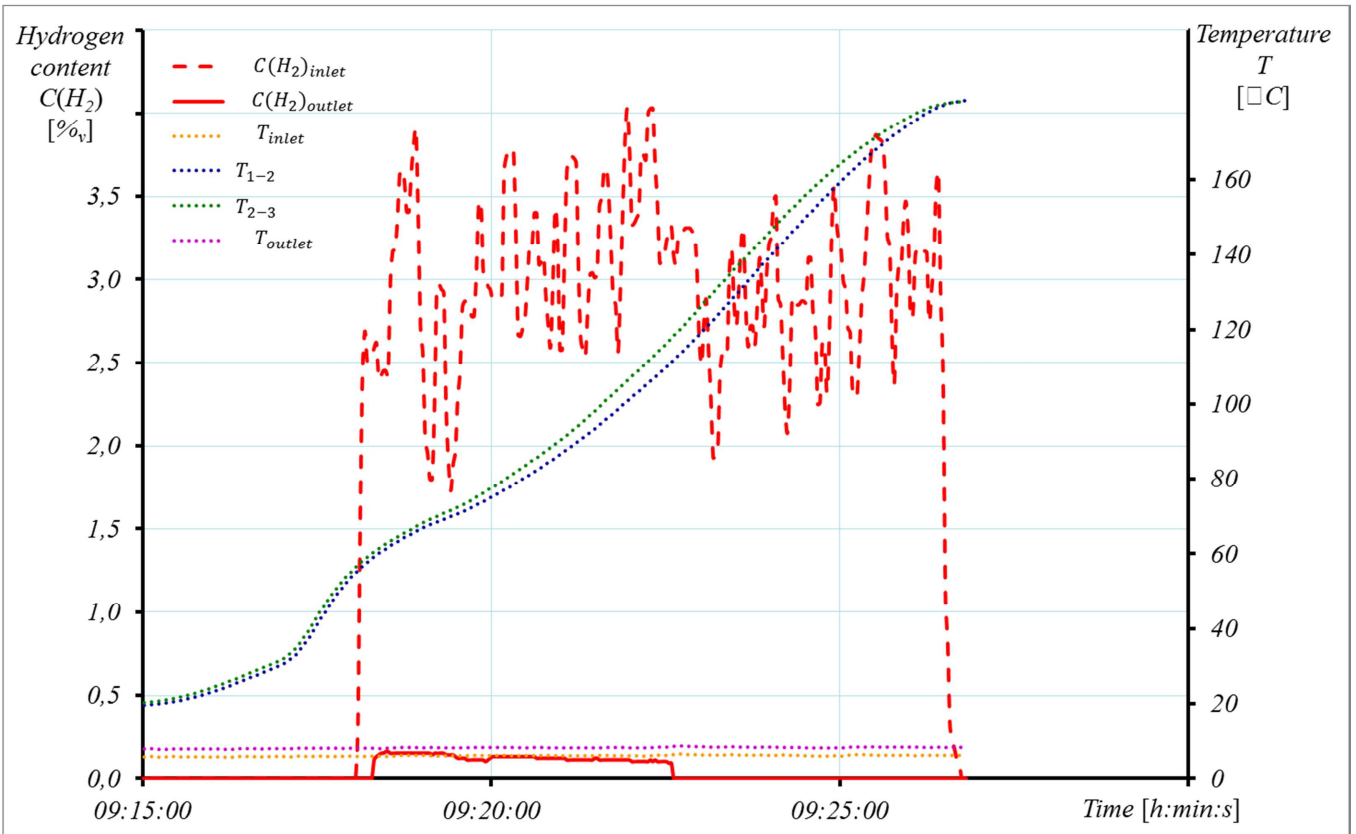

Fig. 6. Test results for the proposed final bed configuration composed of the following catalyst pallets: platinum $0.5 \% \mathrm{~m}$ Pt, GA $-20 \mathrm{Pt}$ type, palladium $0.5 \% \mathrm{~m}$ Pd, GA - 50Pd type and two traditional catalyst pallets.

It was technically possible to conduct tests on all bed configurations - FFE 16 . Such an experimental cycle with repetitions would be ensured with a model ${ }^{17}$ for which an optimal solution could be found. However, the imposed time constraints of the project did not allow for the conduction of complex tests on bed configurations. Thus, the cognitive chance and opportunity to design an intelligent technical solution was wasted.

According to the previous expectations, the test results indicate the possibility of maintaining the thus far applied constructional solution of the incinerators, and the partial filling of the pallets with the new catalysts; in such a scenario it is possible to ensure ventilation at the required level of $\dot{V}_{0} \cong 140 \mathrm{~m}^{3} \cdot \mathrm{h}^{-1}$. With the proposed catalytic bed configuration it is possible to obtain a nearly zero hydrogen concentration level at the incinerator outlet, with its inflow concentration reaching $C\left(H_{2}\right) \cong 3 \%_{v}$.

The observed hazard, of damaging the catalyst bed and the incinerator itself connected with the strong exothermic effect of catalytic hydrogen combustion reaction, suggests the need for incinerator modernisation, consisting in the application of interstage cooling. Certain cooling solutions had already been tested with good results [1]. However, situations connected with a sudden increase in hydrogen concentrations in battery compartments, with the hydrogen content monitoring utilised on the vessel, is rather unlikely.

Besides that, ventilation activation causes an immediate decrease in hydrogen concentration, as there is no reason to assume that hydrogen emission from battery cells can remain at a significant level over a long period of time. An elevated and dangerous hydrogen emission may occur only in the case of a long-standing forced battery charge and an urgent necessity to perform immersion. However, such a procedure assumes continuous ventilation of battery compartments during the charging process in an open-circuit system. At the moment of taking the decision regarding the sealing of the vessel prior to immersion, the system of battery compartment ventilation is switched over to an internal circuit by the hydrogen incinerators. Hence, we should assume that the compartments are perfectly ventilated. Also, during fast immersion there is no need to discontinue ventilation as the noise generated during a combat immersion and escape from the region is so considerable that the additional noise of ventilation fans only slightly increases the total noise level. For these reasons the implementation of an emergency cooling system is not justified through tactical and technical considerations.

The zero hydrogen content level obtained repeatedly at the incinerator outlet is a result that significantly exceeds the initial quality requirements $C T Q$ for acceptance tests.

It was decided to maintain the already determined bed configuration, although placement of a traditional catalyst at the beginning seems to be a better solution. However, this variant was not tested during factorial trials. Due to the imposed time constraints and pressure of the Shipyard, the hydrogen incinerators were moved to the process inspection phase following a shortened improvement phase.

\section{Process InSPECTION PHASE}

The results of the conducted acceptance tests did not depart from the results of previous tests. Due to the acceptance of the performed modernisation of the hydrogen incinerators the systems were reinstalled on the submarine. The vessel with the installed incinerators was handed over.

The assembly of the hydrogen combustion system on the submarine did not involve any special recommendations or application of scale-up methods, nor did it require repetition of any tests on the actual vessel 
due to having performed the tests on an actual shipboard installation. The only difference rested in shortening the route of the hydrogen-air mix and simulation of a battery compartment with the use of a pipe reactor to obtain hydrogen-air mixes. These changes could have an effect only on a reduction of the ventilation stream, which was simulated during the acceptance tests by lowering the flow value to the level of $\dot{V}_{0} \cong 120 \mathrm{~m}^{3} \cdot \mathrm{h}^{-1}$.

\section{CONCLUSION}

The plan for the implementation of modernised incinerators on a submarine encompassed several following guidelines regarding the process of their operation.

Due to the theoretical danger of catalyst overheating, leading to its partial deactivation or damage, it is required to avoid long periods of operation of $t>20 \mathrm{~min}$ with high hydrogen concentrations of $C_{H_{2}}>2 \%$. However, such situations are not likely, as there is no reason to assume that hydrogen emission from battery cells can remain at a significant level over a long period of time.

Dangerous hydrogen emission may occur in a situation where the decision is taken for an immediate immersion following long-term forced battery charging on the surface. In the course of charging it is required to perform intensive ventilation of battery compartments in an open-circuit system and following the decision to seal the vessel for diving, the ventilation circuit is to be switched over to the internal mode by the hydrogen incinerators.

Due to the application of new types of catalysts, it is necessary to conduct catalyst activity inspection at the test bench every 3 years. While planning inspections it is necessary to schedule the completion of tests connected with bed configuration optimisation.

Moreover, an introduction of constructional changes should be considered in order to enable the implementation of an emergency cooling system, and temperature monitoring between bed pallets. Our own studies and analysis of the applied and similar solutions allow to conclude that the hydrogen combustion process will be controlled provided that a proper $S O P^{18}$ is maintained in the case of a necessity to ensure longstanding combustion of hydrogen-air mix with a high hydrogen content $>2 \%{ }_{v} \mathrm{H}_{2} /$ air.

It is worth considering development of additional methods for rapid detection of a control loss over the hydrogen combustion process, and effective control recovery procedures. Quick and automatic detection of control loss over the hydrogen combustion process would require additional modernisation, consisting in the introduction of hydrogen content measurements at the incinerator inlet and outlet, and temperature measurement between sections of pallets containing a catalyst coupled with an interstage cooling system.

The said measurements should be supplied with elements enabling their integration with the existing measurement system. Currently, hydrogen content in the ventilation air before the hydrogen incinerators can be calculated on the basis of its concentration measurements in the battery compartments, and behind the incinerator from hydrogen concentration measurements in the section where the stream of air after hydrogen combustion is directed.
The currently applied protection against overheating is based on SOP consisting in the establishment of proper supervision. It could be easily facilitated with the placement of liquid crystal thermometers on the incinerator housing. Such thermometers can take the form of an adhesive tape that highlights when certain temperatures have been exceeded by changing colour or showing a number indicating approximate temperature. 


\section{BIBLIOGRAPHY}

1. Kłos R. Life sustaining systems in a submarine. Gdynia: Polskie Towarzystwo Medycyny i Techniki Hiperbarycznej, 2008. p. 163. ISBN 978-83-924989-4-0;

2. Morfin F., Sabroux J-C, Renouprez A. 2004. Catalytic combustion of hydrogen for mitigating hydrogen risk in case of a severe accident in a nuclear power plant: study of catalysts poisoning in a representative atmosphere. Applied Catalysis B: Environmental. 2004, Vol. 47, pp. 4758 ;

3. Amrousse R., Batonneau Y., Kappenstein Ch. 25 - 28 July 2010. Catalytic Combustion of Hydrogen-Oxygen Cryogenic Mixtures over Cellular Ceramic Based-Catalysts. Nashville, TN : American Institute of Aeronautics and Astronautics, 25 - 28 July 2010. pp. 2010-7055;

4. Krawczyk M., Namiesnik J. 2003. Application of a catalytic combustion sensor (Pellistor) for the monitoring of the explosiveness of a hydrogenair mixture in the upper explosive limit range. Journal of Automated Methods and Management in Chemistry. 2003, Vol. 25, 5, pp. 115-122; doi: 10.1155/S1463924603000208;

5. Bond G.C. 1979. Heterogenous catalysis-Basics and applications. Warsaw : Państwowe Wydawnictwo Naukowe, 1979. ISBN 83-01-00087-2;

6. Barbir F. 2005. PEM Fuel Cell - Theory and Practice. London : Elsevier Academic Press, 2005. ISBN-10: 0-12-078142-5; ISBN-13: 978-0-12078142-3;

7. Kłos R. Removal of oxidable contaminations contained in submarine atmosphere. Polish Maritime Research. 2008, Vol. 57, 3, pp. 67-69;

8. Kłos R. Catalytic combustion of hydrogen in a submarine. Gdynia: Polskie Towarzystwo Medycyny i Techniki Hiperbarycznej, 2015. ISBN 97883-938-322-3-1:

9. Kłos R. Measurement system reliability assessment. Polish Hyperbaric Research. 2015a, Vol. 51, 2.

\section{dr hab. inż. Ryszard Kłos, prof. nadzw.}

AMW

Westerplatte

Zakład Technologii Prac Podwodnych

81 - 103 Gdynia 3, ul. Śmidowicza 69

Tel: +5862627 46, Fax: +586262761

1 technique is understood as a purposeful, rational, theory-based project management,

2 technique is understood here as a branch encompassing material measures and skills in their handling that enable undertaking a targeted activity,

${ }^{3}$ Strengths, Weaknesses, Opportunities, Threats,

${ }^{4}$ vessels equipped with liquid oxygen for powering combustion engines in an underwater position can perform loading under the surface, however the inability to conduct surface and air observation causes that such a long-lasting manoeuvre is also dangerous,

${ }^{5}$ minimisation of emission of nitrogen oxides, carbon monoxide and unburned hydrocarbons,

${ }^{6}$ in mines they enable the use of typical combustion engines to power many machines, e.g. transport vehicles,

${ }^{7}$ clusters,

${ }^{8}$ known as Critical to Quality,

${ }^{9}$ pellistors (a combination of words pellet and resistor) are porous ceramic elements containing a particular catalytic material with a platinum wire enabling the flow of electrical current heating the component up to several hundred degrees Celsius. If as a result of catalytic hydrogen oxidation the temperature increases the wire resistance should proportionally increase. Changes in resistance constitute an analytical signal,

${ }^{10}$ known as Reliability and Reproducibility,

${ }^{11}$ known as Quality Function Deployment,

12 for example, increasing of fan efficiency,

${ }^{13}$ safety issues have been discussed in the third article in the series that will be published at a later date,

${ }^{14}$ here 'model' is understood as possibly most simplified system operating analogically to the original one in terms of the analysed functionalities,

${ }^{15}$ known as Design of Experiments,

${ }^{16}$ known as Full Factorial Experiment,

${ }^{17}$ multidimensional response space,

${ }^{18}$ Standard Operational Procedure. 